\title{
Survival in Patients With Severe Lymphopenia Following Treatment With Radiation and Chemotherapy for Newly Diagnosed Solid Tumors
}

\author{
Stuart A. Grossman, MDª Susannah Ellsworth, MDª Jian Campian, MD, PhDº; Aaron T. Wild, MD; \\ Joseph M. Herman, MD; ; Dan Laheru, MD; ; Malcolm Brock, MDª Ani Balmanoukian, MD'; and \\ Xiaobu Ye, MDa
}

\begin{abstract}
Background: The immune system plays an important role in cancer surveillance and therapy. Chemoradiation can cause severe treatmentrelated lymphopenia (TRL) $\left(<500\right.$ cells $\left./ \mathrm{mm}^{3}\right)$ that is associated with reduced survival. Materials and Methods: Data from 4 independent solid tumor studies on serial lymphocyte counts, prognostic factors, treatment, and survival were collected and analyzed. The data set included 297 patients with newly diagnosed malignant glioma $(\mathrm{N}=96)$, resected pancreatic cancer $(\mathrm{N}=53)$, unresectable pancreatic cancer ( $\mathrm{N}=101)$, and non-small cell lung cancer $(\mathrm{N}=47)$. Results: Pretreatment lymphocyte counts were normal in $83 \%$ of the patient population, and no patient had severe baseline lymphopenia. Two months after initiating chemoradiation, $43 \%$ developed severe and persistent lymphopenia $(P=.001)$. An increased risk for death was attributable to TRL in each cancer cohort (gliomas: hazard rate $[\mathrm{HR}], 1.8 ; 95 \% \mathrm{Cl}, 1.13-2.87 ;$ resected pancreas: $\mathrm{HR}, 2.2 ; 95 \% \mathrm{Cl}, 1.17-4.12$; unresected pancreas: $\mathrm{HR}, 2.9 ; 95 \% \mathrm{Cl}, 1.53-5.42$; and lung: $\mathrm{HR}, 1.7 ; 95 \% \mathrm{Cl}, 0.8-3.61)$ and in the entire study population regardless of pathologic findings (HR, 2.1; 95\% Cl, 1.54-2.78; $P<.0001)$. Severe TRL was observed in more than $40 \%$ of patients 2 months after initiating chemoradiation, regardless of histology or chemotherapy regimen, and was independently associated with shorter survival from tumor progression. Conclusions: Increased attention and research should be focused on the cause, prevention, and reversal of this unintended consequence of cancer treatment that seems to be related to survival in patients with solid tumors. (J Natl Compr Canc Netw 2015;13:1225-1231)
\end{abstract}

\section{Background}

The immune system has long been thought to be important in the prevention and control of cancer. Pathologic studies have demonstrated that patients with certain common solid tumors (including breast, ovarian, and colorectal cancers) that have intense lymphocytic infiltrates have improved progression-free and overall survival compared with those who do not. ${ }^{1-5}$ Patients

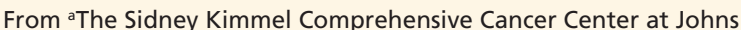
Hopkins, Baltimore, Maryland; 'Washington University, St. Louis, Missouri; 'Memorial Sloan Kettering Cancer Center, New York, New York; and ${ }^{\mathrm{d} T h e}$ Angeles Clinic and Research Institute, Los Angeles, California.

Submitted February 27, 2015; accepted for publication August 3, 2015.

The authors have disclosed that they have no financial interests, arrangements, affiliations, or commercial interests with the manufacturers of any products discussed in this article or their competitors.

Correspondence: Stuart A. Grossman, MD, The Sidney Kimmel Comprehensive Cancer Center at Johns Hopkins, Cancer Research Building \#2, Suite 1M-16, 1550 Orleans Street, Baltimore, MD 21231. E-mail: grossman@jhmi.edu
}

with solid tumors and lymphoma who have comorbidities that cause immunosuppression (eg, HIV infection) or who have idiopathic decreases in the lymphocyte count at baseline have worse survival outcomes than those with entirely normal immune systems. ${ }^{6-9}$ In addition, cancer cells have been found to use a variety of strategies to induce host immunosuppression. ${ }^{10-12}$ These and other related observations provided the justification for the extensive research efforts that have been focused on developing vaccines and other novel immunologic approaches to cancer therapy.

Severe postradiation lymphopenia was originally described in the 1960s and 1970s in patients with brain, uterine, breast, lung, and cervical cancers. ${ }^{13-17}$ These observations were accompanied by concerns that this iatrogenic immunosuppression could interfere with the body's ability to identify and destroy tumor cells. ${ }^{13,18}$ However, until recently, the lymphopenia observed after antineoplastic therapy was not formally associated with 
Grossman et al

inferior patient outcomes. ${ }^{19}$ Consequently, comparatively little attention has been paid to pretreatment or posttreatment lymphocyte counts as a prognostic factor in patients with cancer, as evidenced by the fact that lymphopenia is not generally used as a stratification factor in clinical trials for any solid tumor.

The first formal association between treatmentrelated lymphopenia (TRL) and survival was reported in a prospective trial designed to assess the frequency, severity, duration, and consequences of TRL in patients with newly diagnosed high-grade gliomas. ${ }^{20}$ These patients received 3 highly lymphotoxic therapies: radiation, glucocorticoids, and temozolomide. Forty percent of patients developed grade III/IV reductions in CD4 and total lymphocyte counts; this severe lymphopenia persisted for more than 1 year. Multivariate analysis revealed these significant reductions in CD4 counts at 2 months to be an independent predictor of survival. Recent reports in patients with other cancers, including non-small cell lung cancer (NSCLC) and unresected and resected pancreatic cancer, suggested that the association between TRL and survival might not be limited to high-grade gliomas. ${ }^{21-23}$ As a result, we performed this analysis to summarize the association between TRL and survival using data from 4 studies involving 297 patients with newly diagnosed malignant gliomas, pancreatic cancer, and stage III NSCLC.

\section{Materials and Methods}

This study was approved by the Johns Hopkins Medicine Institutional Review Board.

\section{Study Sample}

This was a meta-analysis of 4 data sets with available complete primary data. One data set was prospective, whereas the others were retrospective. The prospective trial was conducted by the $\mathrm{NIH}$-funded New Approaches to Brain Tumor Therapy Central Nervous System (CNS) Consortium. ${ }^{24}$ The retrospective cohorts identified newly diagnosed patients with resected pancreatic cancer, unresectable pancreatic cancer, and stage III NSCLC who had been treated at Johns Hopkins Medicine institutions. ${ }^{21-23}$ Each of these cohorts included only patients who (1) were previously untreated; (2) were 18 years of age or older; (3) had an ECOG performance status of 0 to 1 ; (4) received concurrent chemoradiation; (5) had pretreatment and monthly follow-up blood counts performed at a Johns Hopkins Medicine institution; and (6) had reliable survival data. In addition, the medical records from each patient were reviewed to acquire information on baseline prognostic factors known to be important for each tumor type and for details of their initial radiation and chemotherapy. Patients were excluded if they had received any prior chemotherapy or radiation.

\section{Ascertainment of Baseline Measures and Follow-Up Events}

The procedures used to obtain data on demographic characteristics, prognostic variables, laboratory results, opportunistic infections, and survival for each cohort have been previously reported. ${ }^{20-23}$ Pretreatment data were collected before the start of radiation in all patients, including those who received induction chemotherapy, and included a CBC, total lymphocyte counts (TLCs), ECOG performance status, and tumor stage. The total dose, number of fractions, and duration of radiation, and the details of the administered chemotherapy were recorded. In addition, CBCs and TLCs were recorded from blood counts obtained after completing combined radiation and chemotherapy, and monthly thereafter for a total of 12 months. Baseline TLCs were classified as normal $\left(\geq 1000\right.$ cells $\left./ \mathrm{mm}^{3}\right)$ or abnormal $\left(<1000\right.$ cells $\left./ \mathrm{mm}^{3}\right)$. After the initiation of antineoplastic treatment, the NCI's Common Terminology Criteria for Adverse Events (CTCAE) Version 4.0 was used to classify the severity of TRL. For the purposes of this study, grade III/IV lymphopenia $\left(<500\right.$ cells $\left./ \mathrm{mm}^{3}\right)$ was considered severe. For patients with missing lymphocyte counts at 2 months, the TLCs at 1 month were used. Overall survival time was measured from the date of diagnosis to the date of death from any cause, and was used as the primary outcome measure in this study, because reliable data on other outcomes, such as progression-free survival, disease-specific survival, local control, and patterns of failure, were not uniformly available. Survival was censored if the subject was alive at the time of last follow-up.

\section{Statistical Analysis}

General statistical methods have been reported for each individual study cohort. ${ }^{20-23}$ Severe TRL was defined as grade III/IV lymphopenia $\left(<500\right.$ cells $\left./ \mathrm{mm}^{3}\right)$ at 2 months after initiating radiation for all study patients. Survival probability was estimated using the Kaplan-Meier method. ${ }^{25}$ The CI of median survival 
time was constructed by the method of BrookmeyerCrowley. ${ }^{26}$ The hazard of death attributable to TRL was estimated using proportional hazards regression modeling. ${ }^{27}$ Heterogeneity among the adjusted hazard ratios (HRs) was determined using the Q, a Chisquare statistic, and the $I^{2}$ statistic. ${ }^{28,29}$ Severe heterogeneity was defined as a $Q$ test at a significance level of $P$ less than .05 and an $\mathrm{I}^{2}$ value greater than $50 \%$. The pooled HR with 95\% CI was constructed using a fixed effects model. ${ }^{30}$ All $P$ values were reported as 2 -sided, and all analyses were conducted using SAS software, version 9.2 (SAS Institute, Cary, NC). The test for heterogeneity was performed using Microsoft Office Excel 2007.30

\section{Results}

\section{Baseline Characteristics of Patients}

A total of 297 patients with newly diagnosed highgrade gliomas, pancreatic cancer, and lung cancer are included in this report. Details regarding the characteristics of each study cohort are provided in Table 1. Baseline demographic information on these patients and details of the radiation, chemotherapy, and use of corticosteroids are also provided in Table 1. The overall median age of the patients was 61 years (range, $28-85$ years), and $75 \%$ of the patients were older than 55 years. Fifty-five percent were men, $85 \%$ were white, and $71 \%$ had a baseline ECOG performance status of zero.

\section{Development of TRL}

The median TLC for all patients before chemoradiation was 1481 cells $/ \mathrm{mm}^{3}$ (range, 331-5030 cells/ $\mathrm{mm}^{3}$ ), with $83 \%$ having a baseline TLC of 1000 cells $/ \mathrm{mm}^{3}$ or greater (Table 2). Two months after beginning radiation and chemotherapy, the median TLC decreased from a median of 1481 to 560 cells/ $\mathrm{mm}^{3}(P<.001) ; 43 \%$ of patients developed grade III/ IV lymphopenia. The findings in each patient cohort are remarkably similar (Figure 1 ). The rapid reduction in lymphocyte counts for the pooled population is graphically represented in Figure 2, where it is also apparent that the median TLC remained less than 1000 cells $/ \mathrm{mm}^{3}$ for the entire 1-year observation period. Baseline demographics, tumor staging, laboratory values, and antineoplastic therapy received were similar in patients who did and did not develop severe lymphopenia 2 months after beginning chemoradiation. ${ }^{20-23}$ Notably, patients with stage III NSCLC who received neoadjuvant chemotherapy did not develop lymphopenia until they began treatment with radiation. ${ }^{21}$

\section{Relationships Between Severe TRL and Overall Survival}

In the pooled data set and in each individual study cohort, there was an association between severe TRL and shorter survival from tumor progression. Table 3 and Figure 3 present the differences in median survival based on posttreatment lymphocyte counts and univariate and multivariate associations between severe TRL and overall survival. Overall, 43\% of the 297 patients developed severe TRL. The Kaplan-Meier survival curve comparing outcomes for those who did and did not develop severe TRL using the combined population from the 4 cohorts is presented in Figure 4. The results of the test for heterogeneity among the adjusted HRs, $Q=1.7(P>.5)$ and $\mathrm{I}^{2}=0 \%$, indicate no significant heterogeneity among the HRs of the 4 individual study

\section{Table 1 Cohort Characteristics, Baseline Data, and Treatment Administered}

\begin{tabular}{|c|c|c|c|c|c|}
\hline & $\begin{array}{l}\text { Pooled } \\
\text { Data }\end{array}$ & Malignant Glioma & $\begin{array}{l}\text { Resected Pancreatic } \\
\text { Cancer }\end{array}$ & $\begin{array}{l}\text { Unresectable } \\
\text { Pancreatic Cancer }\end{array}$ & Stage III NSCLC \\
\hline Size of study, $n$ & 297 & 96 & 53 & 101 & 47 \\
\hline Type of study & & Prospective & Retrospective & Retrospective & Retrospective \\
\hline Date of diagnosis & & $2003-2007$ & $1997-2008$ & $1997-2011$ & $1996-2008$ \\
\hline $\begin{array}{l}\text { Median age, y } \\
\text { (range) }\end{array}$ & $61(28-85)$ & $57(28-85)$ & $64(47-84)$ & $62(55-69)$ & $59(37-79)$ \\
\hline Male sex, n (\%) & $151(51)$ & $48(50)$ & $29(55)$ & $57(56)$ & $17(36)$ \\
\hline $\mathrm{KPS} \geq 80, \mathrm{n}(\%)$ & $210(71)$ & $90(94)$ & $33(62)$ & $57(56)$ & $30(64)$ \\
\hline Chemotherapy & & Temozolomide & Gemcitabine/5-FU & Gemcitabine/5-FU & Platinum doublet \\
\hline Radiation dose (Gy) & & 60 & 50 & $50-59$ & $43-70$ \\
\hline Steroid use & & Yes & No & No & No \\
\hline
\end{tabular}

Abbreviation: KPS, Karnofsky performance status; NSCLC, non-small cell lung cancer. 
Grossman et al

\begin{tabular}{|llllll|}
\hline \multicolumn{2}{|l}{ Table 2 Severity and Frequency of Posttreatment Lymphopenia } & & \\
& Pooled Data & Malignant Glioma & $\begin{array}{l}\text { Resected } \\
\text { Pancreatic Cancer }\end{array}$ & $\begin{array}{l}\text { Unresectable } \\
\text { Pancreatic Cancer }\end{array}$ & Stage III NSCLC \\
\hline $\begin{array}{l}\text { Baseline TLC, } \\
\text { median (range) }\end{array}$ & $1484(331-5,030)$ & $1418(331-4,736)$ & $1945(580-4,200)$ & $1455(426-5,030)$ & $1510(570-3,336)$ \\
$\begin{array}{l}\text { TLC 2 months after } \\
\text { starting radiation, } \\
\text { median (range) }\end{array}$ & $560(0-4,074)$ & $635(49-1,683)$ & $610(0-4,074)$ & $560(100-2,960)$ & $500(131-2,040)$ \\
$\begin{array}{l}\text { TLC reduction at 2 } \\
\text { months }\end{array}$ & $63 \%$ & $58 \%$ & $67 \%$ & $63 \%$ & $61 \%$ \\
$\begin{array}{l}\text { Patients at 2 } \\
\text { months with grade } \\
\text { III/IV TRL }\end{array}$ & $43 \%$ & $37 \%$ & $45 \%$ & $46 \%$ & $49 \%$ \\
\hline
\end{tabular}

Abbreviations: NSCLC, non-small cell lung cancer; TLC, total lymphocyte count; TRL, treatment-related lymphopenia.

cohorts. The pooled HR indicates a 2-fold increase in the risk of early death associated with severe TRL (HR, 2.1; 95\% CI, 1.54-2.78; P<.0001; Figure 3).

\section{Discussion}

Although pretreatment lymphopenia has previously been identified as an important prognostic factor for

\section{A}

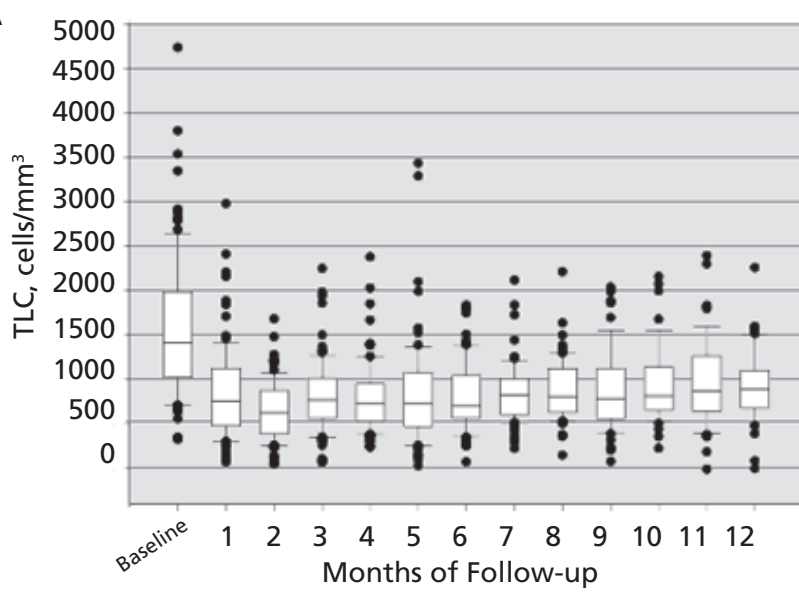

C

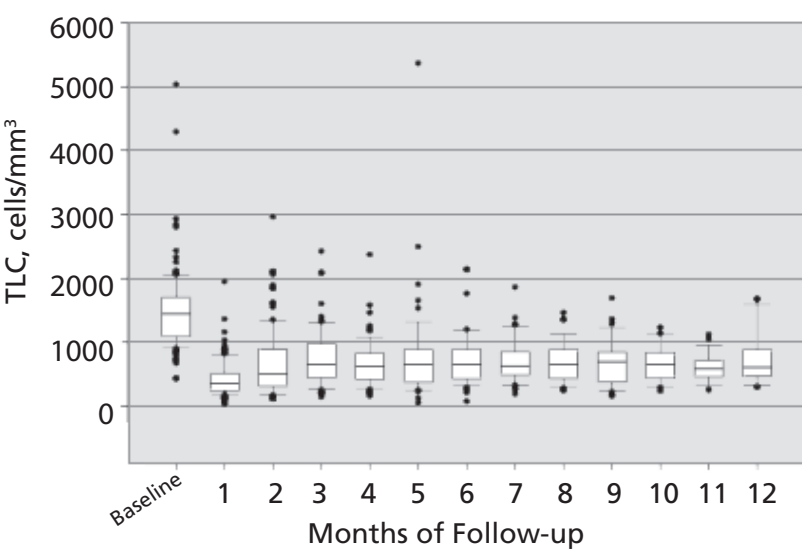

patients with selected solid tumors, ${ }^{9}$ the data presented in this manuscript conclusively demonstrate an association between TRL and survival in patients with a variety of different solid tumors. The patients included in the present analysis all received external beam radiation but were treated with variable chemotherapy regimens, and with and without the use of corticosteroids. When these and other clinical fac-

B
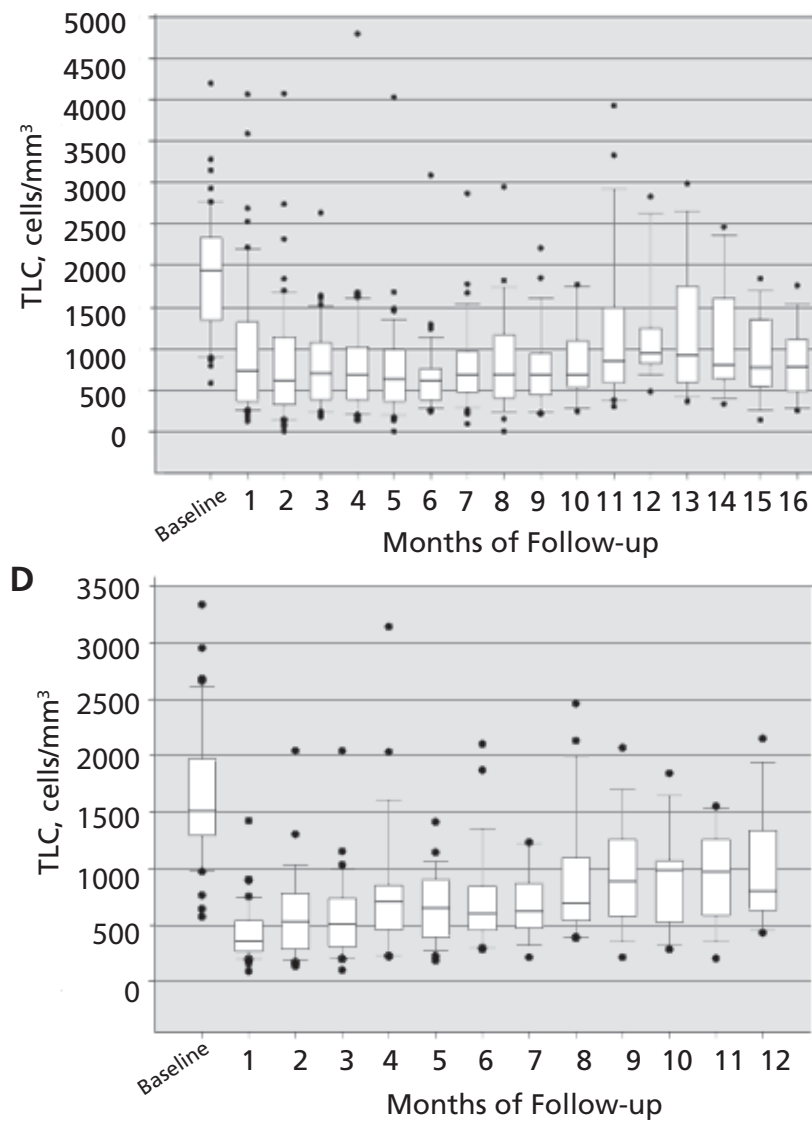

Figure 1 Changes in total lymphocyte count (TLC) over time in each individual disease cohort: (A) high-grade glioma; (B) resected pancreas cancer; (C) unresected pancreas cancer; and (D) non-small cell lung cancer. 
Treatment-Related Lymphopenia and Survival

Table 3 Relationships Between Survival and Grade III/IV Treatment-Related Lymphopenia

\begin{tabular}{|c|c|c|c|c|c|}
\hline & Pooled Data & $\begin{array}{l}\text { Malignant } \\
\text { Glioma }\end{array}$ & $\begin{array}{l}\text { Resected } \\
\text { Pancreatic Cancer }\end{array}$ & $\begin{array}{l}\text { Unresectable } \\
\text { Pancreatic Cancer }\end{array}$ & Stage III NSCLC \\
\hline $\begin{array}{l}\text { Median survival, } \\
<500 \text { vs }>500 \\
\text { lymphocytes }\end{array}$ & 15 vs $18 \mathrm{mo}$ & 16 vs $18 \mathrm{mo}$ & 14 vs $20 \mathrm{mo}$ & $9 \mathrm{vs} 13 \mathrm{mo}$ & 22 vs $27 \mathrm{mo}$ \\
\hline $\begin{array}{l}\text { Univariate hazard } \\
\text { ratio }(95 \% \mathrm{Cl})\end{array}$ & & $\begin{array}{l}1.8(1.10-2.77) ; \\
P=.02\end{array}$ & $\begin{array}{l}1.8(0.995-3.300) ; \\
P=.05\end{array}$ & $\begin{array}{l}1.6(1.04-2.43) ; \\
P=.03\end{array}$ & $\begin{array}{l}1.34(0.70-2.57) \\
P=.38\end{array}$ \\
\hline $\begin{array}{l}\text { Multivariate } \\
\text { hazard ratio } \\
(95 \% \mathrm{Cl})\end{array}$ & $\begin{array}{l}2.1(1.54-2.78) ; \\
P<.0001\end{array}$ & $\begin{array}{l}1.8(1.13-2.87) ; \\
P=.01\end{array}$ & $\begin{array}{l}2.2(1.17-4.12) ; \\
P=.01\end{array}$ & $\begin{array}{l}2.9(1.53-5.42) ; \\
P=.001\end{array}$ & $\begin{array}{l}1.7(0.80-3.61) ; \\
P=.17\end{array}$ \\
\hline $\begin{array}{l}\text { Adjusted covariates } \\
\text { in multivariate } \\
\text { analysis }\end{array}$ & & $\begin{array}{l}\text { Age, surgery, } \\
\text { histology, KPS, } \\
\text { infection }\end{array}$ & $\begin{array}{l}\text { Baseline lymph } \\
\text { count, node- } \\
\text { positive }\end{array}$ & $\begin{array}{l}\text { Baseline albumin, } \\
\text { baseline BUN, } \\
\text { baseline platelets, } \\
\text { PTV }\end{array}$ & $\begin{array}{l}\text { Age, radiation } \\
\text { dose, neoadjuvant } \\
\text { chemotherapy }\end{array}$ \\
\hline
\end{tabular}

Abbreviations: BUN, blood urea nitrogen; KPS, Karnofsky performance status; NSCLC, non-small cell lung cancer.

tors were controlled for, a relationship between TRL and survival was observed, which appears to be independent of tumor histology, pretreatment prognostic factors (including the baseline lymphocyte count), use of dexamethasone, or the chemotherapy regimen administered. Furthermore, we showed that TRL is common, severe, and unexpectedly long-lasting.

The single common denominator among the treatment regimens studied in this report is radiation. This is highlighted by our previous observation that lymphopenia did not develop in patients with NSCLC during neoadjuvant chemotherapy but occurred rapidly after the initiation of radiation therapy. ${ }^{21}$ Lymphocytes are the most radiosensitive cells in the body, and in vitro studies suggest that the dose required to kill $50 \%$ of the population $\left(D_{50}\right)$ of lymphocytes is approximately $1 \mathrm{~Gy}$, and the $\mathrm{D}_{90}$ is approximately 2 Gy. ${ }^{31}$ Publications from the 1960 s and

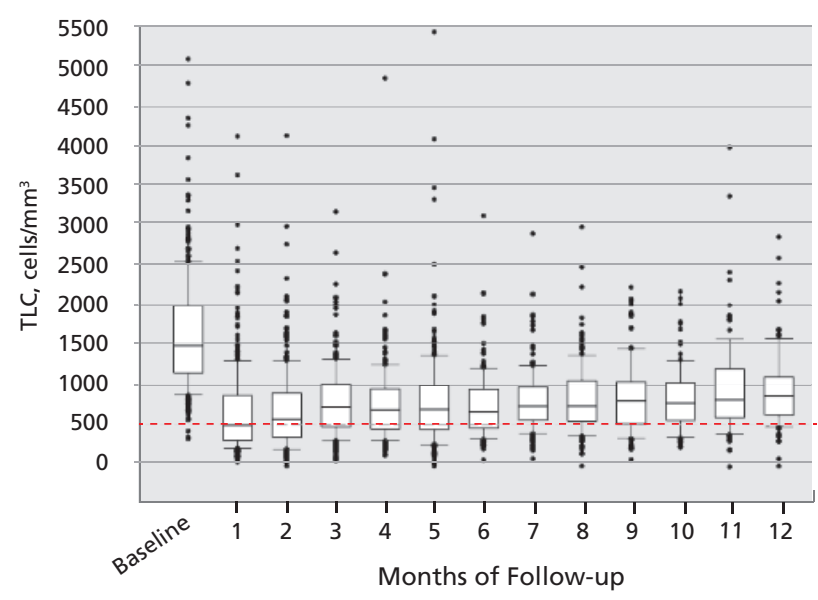

Figure 2 Changes in lymphocyte count over time in the entire group of patients.

Abbreviation: TLC, total lymphocyte count. 1970s noted the development of severe lymphopenia after radiation in patients with brain, breast, cervical, uterine, and lung cancers without the use of concurrent chemotherapy or glucocorticoids. . $^{13,14,16,17,32}$ The radiation oncologists reporting these results expressed concerns that radiation-induced injury to the immune system could negatively affect patient outcomes, but no attempts were made to correlate posttreatment lymphopenia with survival. Nonetheless, accumulating data suggested that postradiation lymphopenia could result from the irradiation of circulating lymphocytes. For example, 94 patients awaiting renal transplant underwent extracorporeal irradiation of the peripheral blood using a cesium source embedded within a shielded dialysis unit in an attempt to induce immunosuppression; this radiation resulted in severe and prolonged lymphopenia. ${ }^{33}$ Additionally, brachytherapy using isotopes with very short path lengths, including radium-226 (range of emitted $\alpha$ particle in tissue, $50 \mathrm{mcm}$ ), iridium-192 (range of emitted $\alpha$ particle in tissue, $2.7 \mathrm{~mm}$ ), and gold-198 (range of emitted $\alpha$ particle in tissue, 4 $\mathrm{mm}$ ), has been shown to cause lymphopenia, with reductions of $30 \%$ to $50 \%$ in the circulating lymphocyte count. ${ }^{34}$ In the same study, oral brachytherapy also was found to cause DNA lesions in circulating lymphocytes that are characteristic of radiation damage (eg, dicentrics and ring chromosomes) and could only have been caused by the irradiation of circulating blood. ${ }^{34}$ Furthermore, we have performed computer modeling studies to calculate the radiation dose administered to circulating lymphocytes during external-beam radiation treatment. ${ }^{30,35}$ This work demonstrated that a typical radiation treatment for glioblastoma (6,000 cGy delivered in 30 fractions to 
Grossman et al

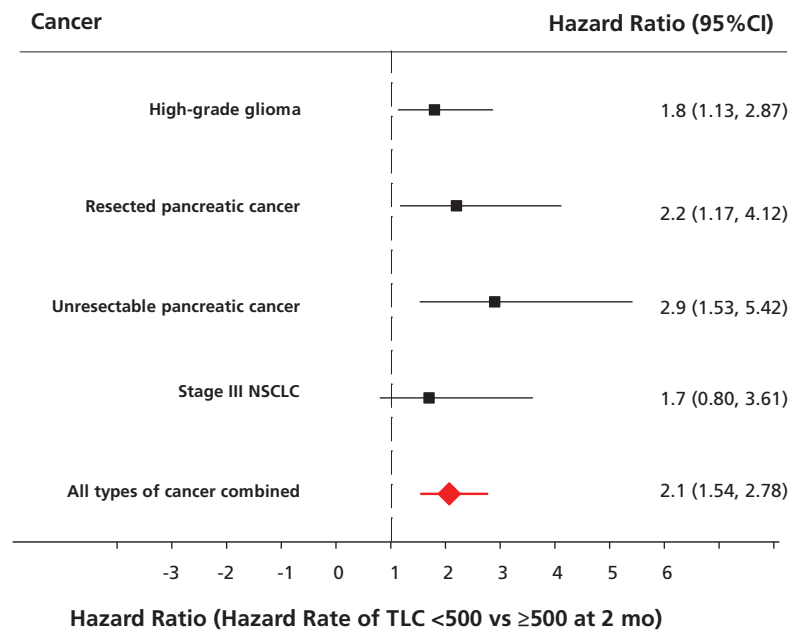

Figure 3 Relationship between survival and grade III/IV treatmentrelated lymphopenia in 297 patients with solid tumors. Pooled hazard ratio, 2.1; $95 \% \mathrm{Cl}, 1.54-2.78 ; P<.0001$.

Abbreviations: NSCLC, non-small cell lung cancer; TLC, total lymphocyte count.

a partial brain field) delivers a potentially toxic dose of radiation to $98 \%$ of the circulating lymphocytes. These data, taken together, strongly suggest that inadvertent radiation of circulating lymphocytes may play a prominent causative role in the development of severe TRL.

These observations do not provide data regarding whether TRL is directly responsible for early tumor progression and death, or whether it is merely a "passenger" accompanying a currently unidentified causative factor that affects the immune system's response to both radiation and malignancies. This important question can best be addressed once strategies are identified to preserve or restore circulating lymphocyte populations during and after chemoradiation. Subsequent clinical trials can then be conducted that randomize patients receiving standard chemoradiation to interventions directed at increasing the circulating lymphocyte count in order to determine if survival improves when treatmentinduced lymphopenia is addressed. For example, approaches such as reinfusion of previously harvested circulating lymphocytes after therapy or the use of exogenous interleukin (IL)-7 could be tested to investigate whether boosting posttreatment lymphocyte counts is associated with an improvement in outcomes. Alternative radiation regimens, particularly hypofractionated treatments, stereotactic radiosurgery, and brachytherapy, could also be tested with the goal of administering "immune-sparing" ra-

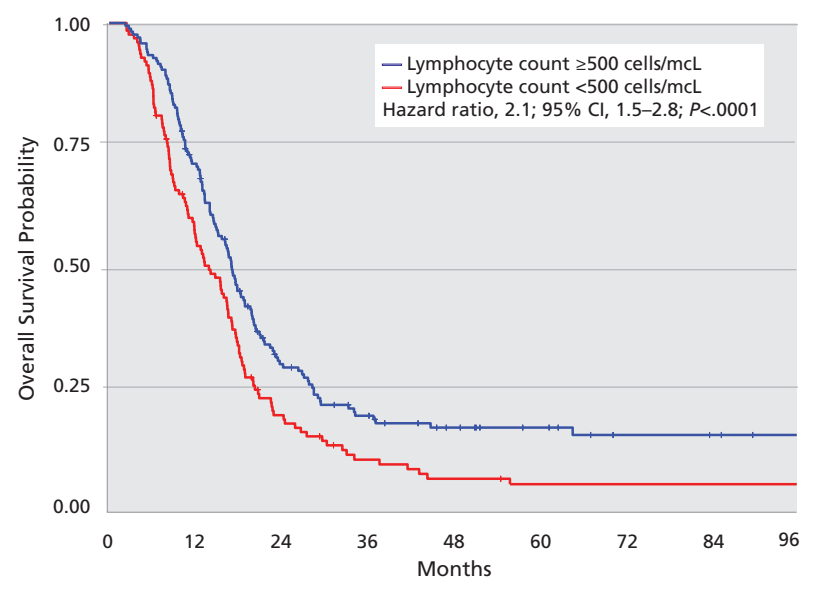

Figure 4 Overall survival (stratified by total lymphocyte count) 2 months after initiating radiation therapy.

diation therapy. In addition, the results described in this manuscript do not provide information regarding which lymphocyte subtypes or related cytokines may be most important in this process, why lymphopenia even after radiation to non-marrow-bearing or nonlymphoid sites such as the brain is so profound and prolonged, and why IL-7 levels may be much lower than expected in these severely lymphopenic patients. ${ }^{36}$ However, our findings strongly suggest that practicing clinicians and researchers should begin to focus on lymphocyte counts as a marker of immunologic status in patients with solid tumors treated with radiation and chemotherapy. An improved understanding of the immunology behind TRL is crucial to developing novel approaches to prevent inadvertent lymphocyte depletion and/or to restore lymphocytes; these interventions have the potential to improve survival in selected patients with relatively treatment-refractory solid tumors.

\section{Acknowledgments}

The authors would like to acknowledge the assistance of Susan Passwaters in manuscript preparation.

\section{References}

1. Bremnes RM, Al-Shibli K, Donnem T, et al. The role of tumor-infiltrating immune cells and chronic inflammation at the tumor site on cancer development, progression, and prognosis: emphasis on non-small cell lung cancer. J Thorac Oncol 2011;6:824-833.

2. Gooden MJ, de Bock GH, Leffers N, et al. The prognostic influence of tumour-infiltrating lymphocytes in cancer: a systematic review with metaanalysis. Br J Cancer 2011;105:93-103.

3. Loi S, Sirtaine N, Piette F, et al. Prognostic and predictive value of tumorinfiltrating lymphocytes in a phase III randomized adjuvant breast cancer 
Treatment-Related Lymphopenia and Survival

trial in node-positive breast cancer comparing the addition of docetaxel to doxorubicin with doxorubicin-based chemotherapy: BIG 02-98. J Clin Oncol 2013;31:860-867.

4. Mei Z, Liu Y, Liu C, et al. Tumour-infiltrating inflammation and prognosis in colorectal cancer: systematic review and meta-analysis. Br J Cancer 2014;110:1595-1605.

5. Oelkrug C, Ramage JM. Enhancement of T cell recruitment and infiltration into tumours. Clin Exp Immunol 2014;178:1-8.

6. Monforte A, Abrams D, Pradier C, et al. HIV-induced immunodeficiency and mortality from AIDS-defining and non-AIDS-defining malignancies. AIDS 2008;22:2143-2153.

7. Grulich AE. Cancer: the effects of HIV and antiretroviral therapy, and implications for early antiretroviral therapy initiation. Curr Opin HIV AIDS 2009; 4:183-187.

8. Le Scodan R, Massard C, Mouret-Fourme E, et al. Brain metastases from breast carcinoma: validation of the radiation therapy oncology group recursive partitioning analysis classification and proposition of a new prognostic score. Int J Radiat Oncol Biol Phys 2007;69:839-845.

9. Ray-Coquard I, Cropet C, Van Glabbeke M, et al. Lymphopenia as a prognostic factor for overall survival in advanced carcinomas, sarcomas, and lymphomas. Cancer Res 2009;69:5383-5391.

10. Vinay DS, Ryan EP, Pawelec G, et al. Immune evasion in cancer: mechanistic basis and therapeutic strategies [published online ahead of print March 25, 2015]. Semin Cancer Biol, doi: 10.1016/j.semcancer.2015.03.004.

11. Zitvogel $\mathrm{L}$, Apetoh $\mathrm{L}$, Ghiringhelli F, et al. The anticancer immune response: indispensable for therapeutic success? J Clin Invest 2008;118:1991-2001.

12. Mellman I, Coukos G, Dranoff G. Cancer immunotherapy comes of age. Nature 2011;480:480-489.

13. Meyer KK. Radiation-induced lymphocyte-immune deficiency. A factor in the increased visceral metastases and decreased hormonal responsiveness of breast cancer. Arch Surg 1970;101:114-121.

14. Raben M, Walach N, Galili U, Schlesinger M. The effect of radiation therapy on lymphocyte subpopulations in cancer patients. Cancer 1976;37:1417-1421

15. MacLennan IC, Kay HE. Analysis of treatment in childhood leukemia. IV. The critical association between dose fractionation and immunosuppression induced by cranial irradiation. Cancer 1978;41:108-111.

16. De Ruysscher D, Waer M, Vandeputte M, et al. Changes of lymphocyte subsets after local irradiation for early stage breast cancer and seminoma testis: long-term increase of activated (HLA-DR+) T cells and decrease of "naive" (CD4-CD45R) T lymphocytes. Eur J Cancer 1992;28A:1729_ 1734.

17. Onsrud M, Grahm I, Gaudernack G. Early stage carcinoma of the uterine cervix. Effects of intracavitary radium treatment on lymphoid cells in blood and pelvic lymph nodes. Acta Radiol Oncol 1986;25:127-130.

18. Fuks Z, Strober S, Bobrove AM, et al. Long term effects of radiation of $T$ and B lymphocytes in peripheral blood of patients with Hodgkin's disease. J Clin Invest 1976;58:803-814.

19. Yovino S, Grossman SA. Severity, etiology and possible consequences of treatment-related lymphopenia in patients with newly diagnosed highgrade gliomas. CNS Oncol 2012;1:149-154.
20. Grossman SA, Ye X, Lesser G, et al. Immunosuppression in patients with high-grade gliomas treated with radiation and temozolomide. Clin Cancer Res 2011;17:5473-5480.

21. Campian JL, Ye X, Brock M, Grossman SA. Treatment-related lymphopenia in patients with stage III non-small-cell lung cancer. Cancer Invest 2013;31:183-188.

22. Wild AT, Ye X, Ellsworth SG, et al. The association between chemoradiation-related lymphopenia and clinical outcomes in patients with locally advanced pancreatic adenocarcinoma. Am J Clin Oncol 2015;38:259-265.

23. Balmanoukian $A, Y e X$, Herman $J$, et al. The association between treatment-related lymphopenia and survival in newly diagnosed patients with resected adenocarcinoma of the pancreas. Cancer Invest 2012;30:571-576.

24. Grossman SA, Ye X, Piantadosi S, et al. Survival of patients with newly diagnosed glioblastoma treated with radiation and temozolomide in research studies in the United States. Clin Cancer Res 2010;16:2443-2449.

25. Kaplan EL, Meier P. Non parametric estimation from incomplete observations. Journal of the American Statistical Association 1958;53:457481.

26. Brookmeyer R, Crowley J. A confidence interval for the median survival time. Biometrics 1982;38:29-41.

27. Cox DR, Oates D. Analysis of survival data. New York, NY: Chapman \& Hall; 1984.

28. DerSimonian R, Laird N. Meta-analysis in clinical trials. Control Clin Trials 1986;7:177-188.

29. Higgins JP, Thompson SG. Quantifying heterogeneity in a meta-analysis. Stat Med 2002;21:1539-1558.

30. Neyeloff JL, Fuchs SC, Moreira LB. Meta-analyses and Forest plots using a Microsoft Excel spreadsheet: step-by-step guide focusing on descriptive data analysis. BMC Res Notes 2012;5:52.

31. Nakamura N, Kusunoki Y, Akiyama M. Radiosensitivity of CD4 or CD8 positive human T-lymphocytes by an in vitro colony formation assay. Radiat Res 1990;123:224-227.

32. MacLennan IC, Kay HE. Analysis of treatment in childhood leukemia. IV. The critical association between dose fractionation and immunosuppression induced by cranial irradiation. Cancer 1978;41:108-111.

33. Weeke E. The development of lymphopenia in uremic patients undergoing extracorporeal irradiation of the blood with portable beta units. Radiat Res 1973;56:554-559.

34. Matsubara S, Horiuchi J, Okuyama T, et al. Chromosome aberrations in the peripheral lymphocytes induced by brachytherapy and external cobalt teletherapy. Int J Radiat Oncol Biol Phys 1985;11:1085-1094.

35. Yovino S, Kleinberg LR, Grossman SA, et al. The etiology of treatmentrelated lymphopenia in patients with malignant gliomas: modeling radiation dose to circulating lymphocytes explains clinical observations and suggests methods of modifying the impact of radiation on immune cells. Cancer Invest 2013;31:140-144.

36. Ellsworth S, Balmanoukian A, Kos F, et al. Sustained CD4+ cell driven lymphopenia without a compensatory IL7/I115 response among high-grade glioma patients treated with radiation and temozolomide. Oncoimmunology 2014;3:e27357. 